\title{
NEGATIVE IMPACTS FROM DISRUPTION OF ROAD INFRASTRUCTURE ELEMENT PERFORMANCE ON DEPENDENT SUBSYSTEMS: METHODOLOGICAL FRAMEWORK
}

\author{
David REHAK ${ }^{*}$, David PATRMAN ${ }^{2}$, Pavel FOLTIN ${ }^{3}$, Zdeněk DVOŘÁK ${ }^{4}$, Viktor SKRICKIJ ${ }^{5}$ \\ ${ }^{1,2}$ Faculty of Safety Engineering, Technical University of Ostrava, Czech Republic \\ ${ }^{3}$ Faculty of Military Leadership, University of Defence, Brno, Czech Republic \\ ${ }^{4}$ Faculty of Security Engineering, University of Žilina, Slovak Republic \\ ${ }^{5}$ Transport and Logistics Competence Centre, Vilnius Gediminas Technical University, Vilnius, Lithuania
}

Submitted 9 July 2021; resubmitted 10 November 2021; accepted 22 November 2021

\begin{abstract}
The critical infrastructure system is determined by subsystems essential for the functioning of the state (such as energy, transport, and emergency services). Disruption to the function of these subsystems would have serious effects on state security, the state economy, and the provisioning of the inhabitants' basic human needs. Links connect these subsystems (i.e., sectors, subsectors, and elements), and these links ensure that certain subsystems are integrated into each other. Their interactions are derived from the type and intensity of the mutual link. The interlinked subsystems can thus be divided into influencing and dependent ones. The aforementioned mutual links in the critical infrastructure system allow, amongst other things, the spread of impacts of disruptive events amongst the subsystems via cascading effects. Disruptions to the performance of an influencing subsystem may have negative effects on a dependent subsystem, resulting in the spread of cascading effects in the critical infrastructure system. Such effects are often difficult to predict, which reduces the responsiveness of the dependent subsystems. Road transport is one of the most significant influences on critical infrastructure subsystems. For this reason, the article focuses on an indication of the negative effects of disruption of road infrastructure elements on dependent subsystems. The article describes the role of road infrastructure in the context of the critical infrastructure system. Defines the dependent subsystems of road infrastructure, categorises the negative effects, and presents a possible approach to assessing the adverse effects of disruption road infrastructure performance on dependent subsystems.
\end{abstract}

Keywords: critical infrastructure, road transport, performance disruption, cascading effect, dependent subsystems.

\section{Introduction}

Critical infrastructure is the term used to describe the system in which the core infrastructures essential for the required operation of the state are protected. A failure of any of these infrastructure elements can threaten the security and economy of the state or inhabitants security (EUCO 2008). The importance of these infrastructures and the topicality of the topic is evidenced, among other things, by the proposal for a new directive of the European Parliament and of the Council (EC 2020) addressing the strengthening of the resilience of critical infrastructure entities (Rehak 2020). One of the fundamental sectors of the critical European infrastructure is transport, allowing smooth traffic on roads. The primary aim in the context of smooth traffic on roads is to provide the overall required performance. The performance of road infrastructure elements can be evaluated from the aspect of their capacity and transport intensity (Patrman et al. 2019). Capacity is defined as the maximum sustainable passage of traffic over a certain period under given road and transport conditions (Jamal 2017). In contrast, intensity expresses the number of vehicles that can pass through a given road section during a specific period (Cools et al. 2010; Ledvinová 2008).

The entire critical infrastructure system consists of subsystems (i.e., sectors, subsectors, and elements) that determine its individual levels. Subsystems have a hierarchical nature, which means that the elements determine the subsectors, the subsectors determine the sectors, and

${ }^{*}$ Corresponding author. E-mail: david.rehak@vsb.cz

Copyright $\odot 2021$ The Author(s). Published by Vilnius Gediminas Technical University

This is an Open Access article distributed under the terms of the Creative Commons Attribution License (http://creativecommons.org/licenses/by/4.0/), which permits unrestricted use, distribution, and reproduction in any medium, provided the original author and source are credited. 
together they make up the entire system. There are links between specific subsystems through which failures can spread in the system. There can be various types of these failures. In their publication, Rinaldi et al. (2001) give 3 types of failures: (1) common, (2) escalating, and (3) cascading. Cascading failures can be considered the most significant type of failure spread in a critical infrastructure system (Rehak et al. 2018). They can cause other failures in the system and the associated disruption or failure of other infrastructures (known as a cascading effect).

One can view the solution to the cascading effect spread within the critical infrastructure from several aspects. By way of occurrence, one can divide the approaches into holistic and reductionist (De Porcellinis et al. 2009). The reductionist approach works with the basic components of the critical infrastructure (known as elements), and it then describes the development of the entire system based on their behaviour. In contrast, the holistic approach deals with the individual sectors or subsectors within the critical infrastructure. In their publication, Setola and Theocharidou (2016) differentiate between the 3 main approaches to modelling the cascading effect spread: (1) holistic, (2) topologic, and (3) simulation-based. Holistic models use simplified models, and they model the sectors and subsectors of critical infrastructure as individual entities. Amongst other things, they can include the method of the Input-output Inoperability Model (IIM). IIM typically uses financial data and is based on the assumption that the influence of various infrastructures can be deduced from their economic influence. Setola et al. (2009), Kelly (2015), Liu and Xu (2013), and others have investigated this method. The topologic (structural) approach comes within the group of network-based approaches. The essence of these approaches is the assumption that all infrastructure is composed of identical elements, consequently composed of nodes on a graph. There are certain relations between the nodes. The topologic approach then identifies the state of each element (node or connection), which may have values fully functional or entirely nonfunctional. Stergiopoulos et al. (2015), Bompard et al. (2009), Min et al. (2007), and others have researched this approach. Simulation-based approaches are distinguished by an attempt to find dependencies arising from the behaviour of individual system components and parts. Johansson and Hassel (2010), Ouyang et al. (2009), Poljanšek et al. (2012), and others have researched this approach. In his publication, Ouyang (2014) gives an overview of other approaches.

A cascading effect may spread through various critical infrastructure subsystems. It can spread through different subsystems or within one subsystem. In their work, Zimmerman and Restrepo (2009) outline the way that a cascading effect spreads through selected critical infrastructure subsystems. This theme has been researched by MacDermott et al. (2014), Barrett et al. (2010) and Serre, Heinzlef (2018), amongst others. From the general traffic aspect, cascading effects have been researched by Dekker and Panja (2021), He et al. (2019) and Cats, Hijner (2021), amongst others. Cascading effects within specific transport subsystems have been researched, e.g., by Lam and Tai (2020), Johansson and Hassel (2010) and Chopra et al. (2016) (i.e., in railway transport); Fekete (2020), Rehak et al. (2020) and Basak et al. (2019) (i.e., in road transport); Cumelles et al. (2021), Du et al. (2018) and Pyrgiotis et al. (2013) (i.e., in air transport).

In conclusion, it must be stated that none of the cited articles covers only the cascading spread of impacts caused by a disruption to the performance of the road infrastructure on dependent subsystems. However, identifying the cascading spread of impacts within a critical infrastructure system is a powerful predictive tool allowing a timely reaction and minimisation of these impacts. For this reason, this article aims to define the dependent subsystems of road infrastructure and categorise the adverse effects in the event of its disruption. In Section 1, critical road infrastructure subsystems are presented, and links between them are defined. In Section 2, dependent subsystems of road infrastructure are presented. The performance of road infrastructure elements is defined in Section 3. In Section 4, assessment of impacts on dependent subsystems arising from disruption to road infrastructure elements' performance is presented. It combines assessing the resilience of dependent subsystems, assessment of the intensity of the link, assessment of disruptive event intensity and comprehensive approach assessing impacts of disruption to performance of road infrastructure elements on dependent subsystems that consists of 7 steps is presented. Conclusions are available in the last section.

\section{Critical road infrastructure subsystems and the links between them}

The term subsystems of critical road infrastructure can describe the main transport structures included in the road network. In road transport, significant motorway sections, tunnels, bridges, rail level crossings and crossroads are generally described as elements of critical infrastructure (Dvořák et al. 2017; Sventekova et al. 2017; AllTraIn 2015). The specified elements can be sub-divided into 3 groups according to their topological structure: (1) point, (2) line, and (3) areal (Rehak et al. 2019).

Specific subsystems can interact within a system based on existing links. These links can exist on the horizontal and vertical levels. The horizontal level indicates links in the area of the subsystem, i.e., between sectors (such as transport or energy), subsectors (such as road or electricity) or elements (such as highways, tunnels, bridges or power plants). The vertical level then represents the links between subsystems, i.e., between elements and subsectors or sectors (such as tunnels and Integrated Rescue System (IRS) or energy) and between subsectors and sectors (such as road transport and energy). The links at both levels within the critical infrastructure system are illustrated in Figure 1. 


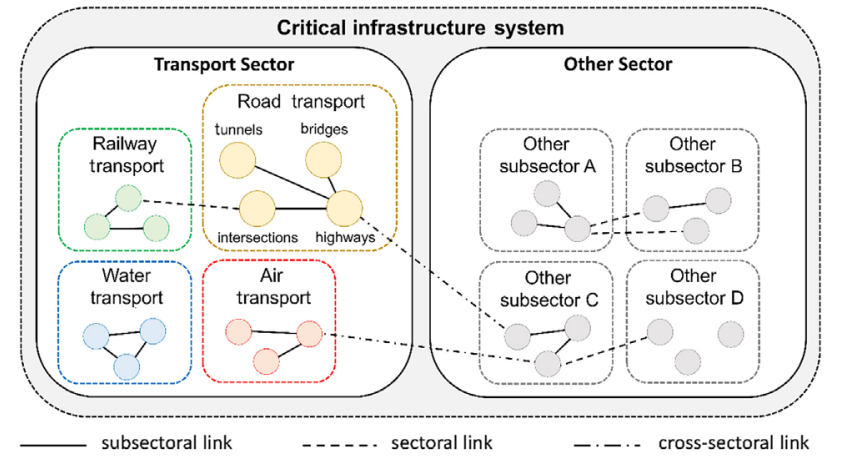

Figure 1. Links in the critical infrastructure system

The links between the individual subsystems are determined by the intensity of these links, which define the extent of their interaction. The intensity of links can be designated based on different determinants. The main ones are the type of link, state of the link, level of link, temporal characteristic of link, the substitution of link and structure of link (Brabcova et al. 2018).

Rinaldi et al. (2001) define 4 types of links: (1) physical, (2) cyber, (3) geographic, and (4) logical. 2 subsystems have a physical link if each state is dependent on the material output(s) of the other. Subsystems have the cyber link if their state depends on information transmitted through the information infrastructure. Subsystems have the geographic link if a local environmental event can create state changes in all of them. 2 subsystems have the logical link if the state of each depends on the state of the other via a mechanism that is not a physical, cyber, or geographic connection. Dudenhoeffer et al. (2006a) offer a different view of categorising links that differentiate between physical, geospatial, policy, and informational links. Lee et al. (2007) and Zhang, Peeta (2011), amongst others, define their types of links.

The state of the link means the way that 2 subsystems influence each other. There are essentially 2 states of link: (1) dependency, and (2) mutual dependency (Rinaldi et al. 2001). Dependency means that subsystem $A$ is dependent on subsystem B, whereas subsystem B is not dependent on subsystem A. Mutual dependency means two-way dependency, i.e., subsystem $A$ is dependent on subsystem $B$, and subsystem B is also dependent on subsystem A. Pederson et al. (2006) further categorise the level of dependency as high, medium and low. Rehak et al. (2016) add influence to the 2 specified types of links: (1) dependency, and (2) mutual dependency. Influence means that subsystems A and B are not dependent on each other, but they can positively or negatively influence each other.

In their article, Brabcova et al. (2018) give other variables defining the link between subsystems - the level of the link, time characteristic of the link, the substitution of the link and structure of the link. The level of the link indicates the level of critical infrastructure on which the link is present. As a result, there is a distinction between the system, sector or subsector link (Setola, Theocharidou 2016). The system level indicates a link representing the dependency or influence of sectors in the context of the entire critical infrastructure system (such as the dependence of the IRS on the road infrastructure). At the sectoral level, this links the dependence or influence of subsectors within a given sector of the critical infrastructure (e.g., the influence of disruption to the road infrastructure on railway transport). The subsectoral level indicates a link representing the dependency or influence of individual elements within a given subsector (such as the dependence of a motorway on a motorway bridge or the influence of a motorway failure on the surrounding roads).

The time characteristic of a link designates the time segment over which a link must act between subsystems to ensure their full functioning (Stergiopoulos et al. 2016). Thus, it is possible to designate a continuous, periodic and emergency link. A continuous link indicates the need for the continuous link of subsystems. In contrast with this, a periodic link occurs at the right time intervals. An emergency link is active only during specific events or upon demand when needed.

The substitution of a link represents replacing an original link with a different one (Ouyang 2014). The absence of a substitution link means the greater intensity of the evaluated link. The existence of such a substitution link, such as a backup electricity source, decreases the intensity of the link.

The structure of the link indicates the interconnection of the link. There is a distinction between a direct link and an indirect link via one node and an indirect one via 2 nodes (Rinaldi et al. 2001). In the case of a direct link, the influencing subsystem directly impacts the dependent subsystem (e.g., the influence of electricity on railway transport). An indirect link via 1 or 2 nodes indicates an indirect impact (such as the influence of electricity on road transport via railway transport).

Subsystems are divided into influential or dependent based on the existence and direction of a link's impact (Rehak et al. 2018). An influential subsystem affects another concrete subsystem. In contrast, a dependent subsystem is subordinated to another subsystem. When performance is disrupted due to cascading failures, this is a situation where the performance of the influential subsystem is disrupted, resulting in a disruption to the performance of the dependent subsystem (e.g., a disruption to the electricity supply will have a negative impact on traffic on electrified railway tracks).

\section{Dependent subsystems of road infrastructure}

Road infrastructure constitutes a significant part of the transportation system, determining the quality of land transport in the country. The functioning of modern transport infrastructure is characteristic of developed states, as shown, e.g., by research (Schwab 2019). The significance of the transport infrastructure (in particular the road infrastructure) is also reflected in the military sector ensuring state security (Vlkovský et al. 2017; Brunclik 
et al. 2018). The transport infrastructure serves primarily for the mobility or logistics. It also allows the other core branches' effective operation that it influences (i.e., dependent subsystems).

Dependent subsystems of the road infrastructure can be identified by using several methods that reveal the links between subsystems. In addition to methods utilising software tools (Setola, Theocharidou 2016; Casalicchio et al. 2010; Dudenhoeffer et al. 2006b), one of the methods for identifying interconnections can also be used. One of these is the method of a qualitative risk analysis utilising correlations of risks (Pacinda 2010). The method was designed to identify the interconnections between potential risks in the industry. However, after a modification, it is also possible to use the method to reveal the interconnections between critical infrastructure subsystems and identify their dependence on road transport.

This article is sufficient to perform certain steps of the KARS (method of a qualitative risk analysis utilizing correlations of risks; in Czech: Kvalitativní Analýza Riziks využitím jejich Souvztažnostî) method (Pacinda 2010). The foundation is the compilation of a table where the critical infrastructure subsystems will be located (Table 1). In this step, important critical infrastructure subsystems were selected, for which a certain connection to road transport can be assumed, either dependent or influential. These critical infrastructure subsystems have been identified using factors influencing the performance of critical transportation infrastructure elements (Patrman et al. 2019). A total of 8 subsystems were identified - road transport, electricity, water supply, railway transport, IRS, healthcare, Information and Communication Technologies (ICT), and fossil fuels and their products. Links between them were sought out in the analysis. When the values 1 (yes) and 0 (no) were filled in, a procedure was applied depending on whether disruption to performance of subsystem $S_{i}$ could disrupt the performance of subsystem $S_{j}$ but where the subsystem cannot influence itself - " $x$ ". Then the values in horizontal and vertical directions of all subsystems were added together.

Based on the sum of the values, the coefficients of activity $C_{A} \cdot S_{i}$ and passivity $C_{P} \cdot S_{j}$ were calculated for the individual subsystems (Table 2). These show what percentage of the specified subsystems is influential in terms of the monitored subsystem (coefficient of activity) and which percentage is dependent (coefficient of passivity). The equations for calculating the coefficients are as follows:

$$
\begin{aligned}
C_{A} \cdot S_{i} & =\frac{\sum_{i=1}^{n} S_{i}}{n-1} \cdot 100 \% ; \\
C_{P} \cdot S_{i} & =\frac{\sum_{i=1}^{n} S_{j}}{n-1} \cdot 100 \% .
\end{aligned}
$$

The results of the KARS method show that the dependent subsystems of the road transport infrastructure are the water supply, railway transport, IRS, and healthcare. Thus, from the calculation of the coefficients of activity and passivity, it is seen that (concerning the specified subsystems) road transport is more of a dependent $\left(C_{P} \cdot S_{j}=71.4 \%\right)$ rather than influential $\left(C_{A} \cdot S_{i}=57.1 \%\right)$ subsystem, but the disruption to the performance of their elements would influence more than half of the specified subsystems.

\section{Defining performance of road infrastructure elements}

We can monitor and assess performance in 2 essential areas in road transport: (1) vehicle transport performance, and (2) transport infrastructure capacity (Patrman et al. 2019).

\begin{tabular}{|c|c|c|c|c|c|c|c|c|c|c|c|}
\hline & \multicolumn{9}{|c|}{ Subsystems $S_{j}$} \\
\hline & & & 1 & 2 & 3 & 4 & 5 & 6 & 7 & 8 & $\sum_{i}$ \\
\hline \multirow{8}{*}{ Subsystems $S_{i}$} & 1 & Road transport & $\times$ & 0 & 1 & 1 & 1 & 1 & 0 & 0 & 4 \\
\hline & 2 & Electricity & 1 & $x$ & 1 & 1 & 1 & 1 & 1 & 0 & 6 \\
\hline & 3 & Water supply & 0 & 1 & $x$ & 0 & 0 & 1 & 0 & 0 & 2 \\
\hline & 4 & Railway transport & 1 & 1 & 0 & $x$ & 0 & 0 & 0 & 0 & 2 \\
\hline & 5 & IRS & 1 & 0 & 0 & 0 & $x$ & 1 & 0 & 0 & 2 \\
\hline & 6 & Healthcare & 0 & 0 & 1 & 0 & 0 & $\times$ & 0 & 0 & 1 \\
\hline & 7 & ICT & 1 & 0 & 0 & 1 & 1 & 1 & $x$ & 0 & 4 \\
\hline & 8 & Petroleum & 1 & 1 & 0 & 1 & 1 & 0 & 0 & $x$ & 4 \\
\hline & & $\sum_{j}$ & 5 & 3 & 3 & 4 & 4 & 5 & 1 & 0 & 25 \\
\hline
\end{tabular}

Table 1. Interconnection of selected critical infrastructure subsystems

Table 2. Coefficients of activity and passivity

\begin{tabular}{|l|c|c|c|c|c|c|c|c|}
\hline Subsystem $S_{i}$ & 1 & 2 & 3 & 4 & 5 & 6 & 7 & 8 \\
\hline Coefficient of activity $C_{A} \cdot S_{i}[\%]$ & 57.1 & 85.7 & 28.6 & 28.6 & 28.6 & 14.3 & 57.1 & 57.1 \\
\hline Coefficient of passivity $C_{P} \cdot S_{j}[\%]$ & 71.4 & 42.9 & 42.9 & 57.1 & 57.1 & 71.4 & 14.3 & 0 \\
\hline
\end{tabular}


Vehicle transport performance is assessed for people mobility and goods transportation. In the case of mobility, performance means the transport of one person over a distance of one kilometre and is calculated as the parameter of transport performance (i.e., the distance driven by a given vehicle), and the number of persons transported $[\mathrm{p}-\mathrm{km}]$. In the case of goods transport, the transport performance represents the transport of one ton of goods over a distance of one kilometre. It is calculated as the product of the transport performance and weight of load [t-km] (Ramanathan 2004).

This text's 2 nd and core area is transport infrastructure constructions, where their transport capacity (Levinson, Kanchi 2002) and traffic volume (Findley et al. 2015) are assessed. Capacity is most often designated for sections of road, tunnels or bridges. The volume is then measurable on-road and motorway sections. Both quantities can theoretically be applied to other road infrastructure buildings. Transport infrastructure capacity is defined as the maximum sustainable passage of traffic over a certain period under given road and transport conditions. In contrast with this, traffic volume expresses the number of vehicles passing through a given road section over a specific unit of time (Cools et al. 2010; Ledvinová 2008).

The transport infrastructure capacity can be classified as design, strategic, and operational (ToL 2013). The design capacity represents the maximum number of vehicles that pass smoothly through a certain point or section under ideal conditions. The strategic capacity represents the maximum number of vehicles that pass smoothly through a certain point or section under the most frequently occurring road, traffic and control conditions at the given place. The operational capacity represents the capacity with the absence of traffic density in such an amount as would cause groundless holdups, danger or restrictions of drivers' freedom, this being under the most frequently occurring road, traffic and control conditions at the given place.

\section{Assessment of impacts on dependent subsystems arising from disruption to the performance of road infrastructure elements}

The impacts arising from a disruption of these elements may spread in 3 directions: (1) remain in the critical infrastructure system, or (2) impact inhabitants, and (3) the environment. This article deals only with the cascading impacts in the critical infrastructure system, so it will not look at social and environmental impacts.

There may be a cascading spread of effects in the critical infrastructure system in the case of existing links between road infrastructure elements and other critical infrastructure subsystems (Rehak et al. 2018). How the effects cascade to other dependent subsystems depends on the components and their variables. These components can be divided into 3 primary groups: (1) the dependent subsystem, (2) the link, and (3) the type of disruptive event. Figure 2 shows the components and variables influencing the cascading spread of a disruption to the performance of road infrastructure elements on their dependent subsystems. The dependent subsystems are marked in blue, while the green line indicates their connection to the influential element of the road infrastructure. The solid line shows the link in the normal state, while the dashed line indicates the link affected by the event in which the performance of the road infrastructure element was disrupted (red).

\subsection{Assessing the resilience of dependent subsystems}

One variable element of dependent subsystems is their resilience. The resilience of a subsystem is designated as the ability to overcome extraordinary events and maintain its functionality during their impact and thus stop a crisis situation from occurring (Rogers et al. 2012; Labaka et al. 2016; Rehak et al. 2019). It is thus an ability that helps maintain its performance element at the highest possible level.

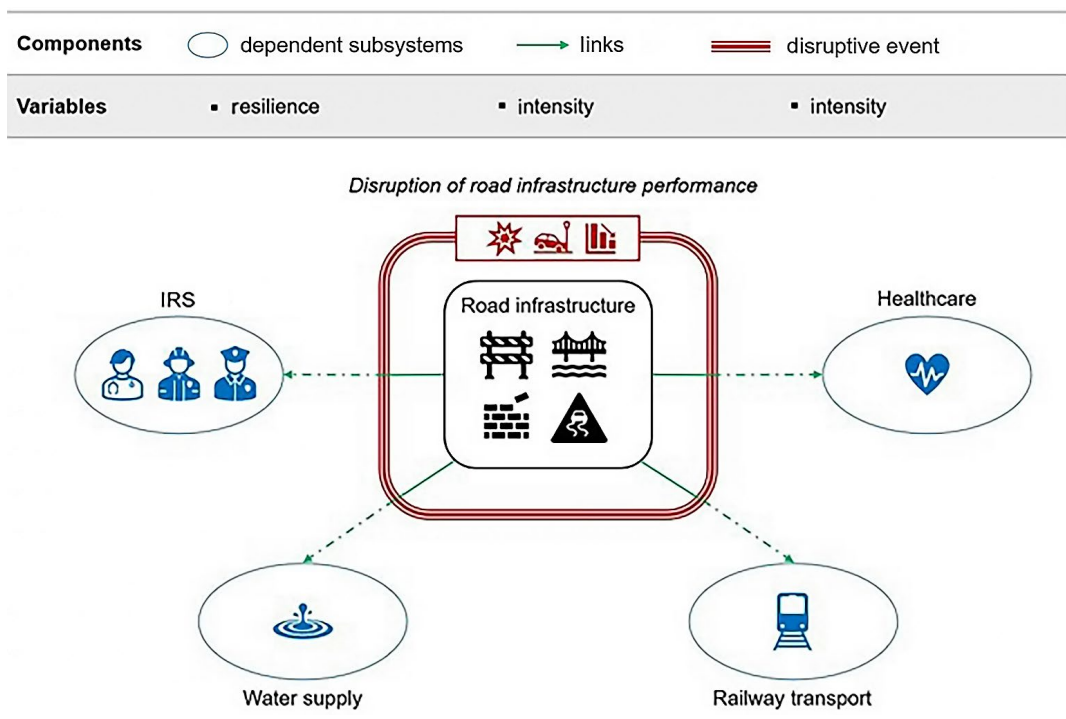

Figure 2. Influence of disruption to performance of road infrastructure elements to dependent subsystems 
The resilience of the dependent subsystems can be measured using specific methods. Precisely, these methods assess the static resilience of critical infrastructure elements (Simonovic, Arunkumar 2016). This resilience assessment method provides information about the level that the element reaches before the impact of the disruptive event.

Specific resilience assessment methods include the Converged Resilience Assessment (CRA) method (Hromada et al. 2021). This method serves to determine the resilience metric for critical electrical engineering infrastructure elements based on converged safety, which combines physical, cybernetic and operational safety. Another method in this area is the Assessing and Strengthening Organisational Resilience (ASOR) method (Rehak 2020). Its essence lies in determining the level and strengthening the organisational resilience of a critical infrastructure entity. Here the overall value of organisational resilience equals the weighted average of the resilience metric of 3 areas: (1) risk management, (2) educational and development processes, and (3) organisational innovation processes.

Rehak et al. (2019) presented the Critical Infrastructure Elements Resilience Assessment (CIERA) method, which serves as a complex assessment and designation of a selected element's resilience metric. The designation of the overall resilience metric here is based on the value of an average of 3 components: (1) robustness, (2) renewability, and (3) adaptability - and each of these components is determined by several variables. Cai et al. (2018) presented a method for designating the availability-based engineering resilience metric. In this method, the resilience metric is designated based on dynamic Bayesian networks in which there are 2 basic types of resilience properties: (1) performance-related, and (2) time-related. Kozine et al. (2018) also focused on the area of assessing the resilience of critical infrastructures. In their work, they presented the READ framework for the procedure of their evaluation. The framework consists of 3 steps on which the actual resilience evaluation is based: (1) specification of system, (2) characteristic of system, and (3) resilience evaluation, and each step includes certain processes. The essence of the evaluation is an assessment of the current and required resilience metric, which is broken down into the preventative, absorptive, adaptive and restorative ability of the given elements.

Nan and Sansavini (2017) also focused on this area, and for these purposes in their work, they presented a quantitative method for assessing the resilience of dependent subsystems. It is based on 2 elements: (1) an integrated metric for quantifying resilience and (2) hybrid multilayer modelling that reflects and quantifies the system's performance throughout the mutual dependencies. In this case, resilience is quantified based on the level of the provided performance of the subsystem in 4 phases: (1) the initial phase before the disruption of performance, (2) the phase during the disruption of performance, (3) the restoration phase and the phase with a new, (4) steady level of provided performance. In his publication, Prior (2015) presents a set of indicators that can measure the resilience metric of critical infrastructure. They divided the indicators into 2 groups: (1) indicators relevant before the start of the disruptive event impacting critical infrastructure and (2) indicators that offer information after such an event has occurred. The last of the presented suitable methods for designating the resilience metric is the Resilience Measurement Index (RMI) method (Petit $e$ t al. 2013). The actual resilience here consists of 4 components: (1) readiness, (2) alleviation measures, (3) responsiveness, and (4) recoverability. Each of the components then branches off into components of the 2nd and 3rd levels. The calculation of the resultant resilience metric is based on a weighted average of the resilience values of the individual components.

It can be seen from the methods described that several components determine the resilience of a subsystem. These components are resistance, robustness, recoverability, and adaptability, which were most frequently present in the specified methods (NIAC 2009; Rehak et al. 2020; Hromada et al. 2021). Each of the components is characterised by a particular ability of the subsystem. Resistance is the ability of a subsystem to prevent the incidence of a disruptive event, including the disruption of its performance. It is preventative, the influence of which is manifested before the disruption of performance. Robustness is a subsystem's ability to absorb the impacts caused by a disruptive event. These impacts can be absorbed by the timely identification and handling of a disruptive event. Renewability is the ability of a system to restore its activity to the original (required) level of provided services after the end of the impacts of a disruptive event. It can be regarded as a certain type of repairability of the subsystem. Adaptability is the ability of a critical infrastructure subject (i.e., an organisation) to prepare the subsystem for the repeated occurrence of a disruptive event that has occurred before. It represents the organisation's dynamic ability (with long-term effect) to adapt to the changed situation. As the subsystem's resilience metric increases, so increase the ability to resist and deal with the impacts of a disruptive event.

The presented methods are characterised by the fact that certain facts can be deduced from them. They can be divided into several groups depending on the content. The 1 st group is the area on which the given method focuses. So, the methods can focus on electricity (Hromada et al. 2021), organisational resilience (Rehak 2020), technical resilience (Cai et al. 2018), associated infrastructure (Nan, Sansavini 2017) or critical infrastructure in general (Rehak et al. 2019; Kozine et al. 2018; Prior 2015; Petit et al. 2013; NIAC 2009). Moreover, it is possible to comprehensively evaluate these methods for just one resilience component or resilience. Some of the methods are indexed, some require or recommend to assess the resilience of a software tool. 
Out of the list of methods given, the CIERA method (Rehak et al. 2019) appears significant based on the described criteria. This method allows the assessor to conduct a clear and comprehensive evaluation of a selected element's resilience using a point evaluation of the designated determinants. Its application is not dependent on the use of any software tool. The essence of the method is applying an unambiguously designated evaluation process based on which output is achieved in the form of the overall resilience metric of the given element. In addition, the resultant evaluation can be used to identify weak points in which it is necessary to strengthen resilience.

\subsection{Assessment of intensity of the link}

The intensity of a selected element of road transport is a variable component determining the link between that element and the dependent subsystem. The intensity of a link expresses the level, dependence or mutual dependence between 2 critical infrastructure elements. Authors studying the evaluation of links between different critical infrastructure subsystems use various approaches to evaluating link intensity in their publications. The following approaches, in particular, are the most important in the given area.

In their article, Brabcova et al. (2018) assess the intensity of links according to a weighted average of 6 determining variables: (1) type, (2) state, (3) level, (4) temporal characteristic, (5) substitution, and (6) structure. Cimellaro (2016) assesses the intensity of links using a matrix representing the degree of individual links between subsystems. The core information is the type of failure and the importance factor. In their publication, Carhart and Rosenberg (2016) give a framework for characterising the dependencies of infrastructures. In their evaluation of the intensity of the link, they work with 12 variables defining it: (1) directionality, (2) order, (3) coupling, (4) location, (5) type, (6) interaction type, (7) functionality, (8) necessity, (9) outcome, (10) life-cycle impact stage, (11) geographic scale, and (12) sectoral scale.

Petit et al. (2015) assess the link intensity based on interactions (in direction, internal, against direction), classes (physical, cybernetic, logical, geographical) and dimensions (operating environment, strength of interaction and response, type of failure, characteristic of infrastructure, operational state). Setola et al. (2009) assess the intensity of a link based on the seriousness in the case of a failure of an influencing subsystem over a specific period (less than $1 \mathrm{~h}, 1 \ldots 6 \mathrm{~h}, 6 \ldots 12 \mathrm{~h}, 12 \ldots 24 \mathrm{~h}$ and $24 \ldots 48 \mathrm{~h})$. McDaniels et al. (2007) presented a framework for characterising infrastructure failure interdependencies. In characterising dependencies, they focused on 4 values influencing the impacts of a potential subsystem disruption and thus defining the link intensity. These values are (1) the duration of the disruption, (2) seriousness of disruption, (3) territorial scope of disruption, and (4) number of impacted persons. Zimmerman and Restrepo (2006) offer a different view of the evaluation of links. Their article groups the influencing subsystems according to significance, which is derived from the condition caused by the disruption of performance by one concrete subsystem compared with the disruption of performance by the other subsystems.

During an examination of the individual approaches, it became evident that some of them assess link intensity only based on one determinant (i.e., duration of failure). In contrast, others assess intensity based on several determinants (such as type of link, duration of failure or territorial scope of disruption). Some approaches allow only a qualitative assessment of links, whereas others focus on a quantitative evaluation. Most of the approaches can be applied to an assessment of the intensity of links between different infrastructures. Concerning the time demands and gaining of the necessary data, it is possible to split the specified approaches into time-demanding and others that can be applied without demanding data gathering.

Based on these criteria, one can state that the Brabcova et al. (2018) approach is a suitable method for assessing link intensity. This approach defines 6 determinants of link intensity: (1) type of link, (2) state of the link, (3) level of link, (4) temporal characteristic of link, (5) the substitution of link, and (6) structure of link. This method is suitable for quantifying the links between selected elements by assigning points to each of the 6 determinants. Its advantage is the relative simplicity and low time demands, whilst at the same time, the required evidentiary value is preserved. The resultant percentage level of the link interprets the extent to which the assessed elements are linked.

\subsection{Assessment of disruptive event intensity}

Just as in the case of link assessment, intensity is a significant variable component for evaluating a disruptive event. The intensity of a disruptive event indicates how much the performance of the given element will be reduced. The reduction can express this in the capacity of a given element (e.g., a tunnel). It will be based on its optimal capacity. The result may then be presented in percent, e.g., an $80 \%$ performance reduction.

The approaches of various authors to this matter were studied to define the determinants of a disruptive event's intensity (see below). The results of this analysis show that none of the authors deals directly with an assessment of a disruptive event's intensity as a whole, and they tend to look at its individual determinants, which are in particular the type and duration of a disruptive event, the impacted territory and number of people impacted by a failure. The following overview explains the determinants themselves and the approaches that mention these determinants.

The type of disruptive event means an event that disrupts the performance of the given element (such as damage to the road tunnel). Disruptive events are typically divided into events of a naturogenic and anthropogenic nature. The Peril Classification (IRDR 2014), e.g., gives an overview of naturogenic events. It classifies naturogenic 
perils in 6 sub-categories: (1) geophysical (e.g., earthquake and volcanic activity), (2) hydrological (e.g., flood and landslide), (3) meteorological (e.g., storms and extreme temperature), (4) climatological (e.g., drought and wildfire), (5) biological (e.g., animal incident and disease), and (6) extraterrestrial (e.g., impacts and space weather).

In his book, Rodrigue (2020) divides naturogenic disruptive events into 4 sub-categories, which are: (1) extreme weather events (such as floods, cyclones, tornadoes), (2) geophysical (such as tectonic activity, earthquakes, tsunamis), (3) geomagnetic storms or (4) sea level. He divides anthropogenic threats into intentional and unintentional, including traffic accidents, infrastructure failure (e.g., insufficient or poor maintenance, shortcomings in design documentation), conflicts, terrorism, piracy (such as wars, civil disorder) and economic and political shocks and pandemics.

Researchers in AllTraIn (2015) project offer an overview of disruptive events threatening specific road infrastructure. They categorise naturogenic threats as meteorological, geophysical, gravitational, hydrological and other. They only distinguish between intentional and unintentional anthropogenic events. Naturogenic and anthropogenic disruptive events also include cascading threats spreading through critical infrastructure subsystems. Rehak et al. (2019) classify cascading threats as technogenic threats along with process-technological threats. An overview of the methods suitable for evaluating cascading effects is given in the introduction to the article.

The duration indicates how long the disruptive event will negatively impact the impacted road infrastructure. It can last minutes, hours or days. The duration of a disruptive event impacting road infrastructure is summarised, e.g., in the works of Voumard et al. (2018), Postance et al. (2017), Keller and Atzl (2014), Marzocchi et al. (2012).

Another determinant of a disruptive event's intensity is the impacted territory, and the area of this territory is fundamental. It can range from units to thousands of square kilometres. The area of an impacted territory has been evaluated by Papilloud et al. (2020), Armenakis et al. (2017), De Moel et al. (2015), and Foudi et al. (2015), amongst others.

The last of the specified determinants is the number of people impacted by a disruptive event. This indicates the number of people whose lives are negatively impacted by the given disruptive event. This may range from single figures to hundreds of thousands of people. Calka et al. (2017), Jacobsen et al. (2016), Theocharidou and Giannopoulos (2015), and Quinn (2013) have all researched the number of people impacted during an evaluation of disruptive event intensity impacting road infrastructure.

Based on the aforementioned, one can assume that it is a good idea to proceed primarily based on 2 approaches when assessing the intensity of a disruptive event; the 1rst (AllTraIn 2015) can be used to define naturogenic and anthropogenic threats that can cause a disruptive event disrupting the performance of road infrastructure, whereas the 2nd (Rehak et al. 2019) can be used to define technogenic threats.

\subsection{Comprehensive approach to impact assessment}

Based on the aforementioned methodological analysis, there is a presentation below of a comprehensive approach to assessing the impacts of a disruption to the performance of road infrastructure elements on dependent subsystems. This approach was created by the article's authors and serves as a quantitative assessment of the level of impacts arising from a disruption to a critical road infrastructure element and an assessment of its further spread to the critical infrastructure dependent subsystems. The structural classification of the individual steps of the approach for assessing impacts, including the commensurate methodology, is presented in Figure 3.

\section{Step 1: Selection of influential element of road infrastructure}

As part of the step 1, one must select the influential element of road infrastructure to be assessed. There are 2 ways to select the influential element: (1) is a personal selection by an evaluator based on knowledge of the specific element, i.e., without using any tool, and (2) is a selection of the influential element using acceptable methods. It is good to use the assessment of critical infrastructure elements in transport (Dvorák et al. 2017) method for this purpose. This method serves to identify critical elements of road and rail transport. Identifying critical elements serves as the basis for ensuring that the given element may be an element influencing other subsystems. The advantage of this method is its usage simplicity and the possibility of application to elements of both local and national significance. The identification is based on the 5 following phases: (1) selection of surface transport subsector, (2) analysis of critical elements and identification of typological elements, (3) definition and application of sectoral criteria, (4) definition and application of crosssectoral criteria, (5) assessment of whether the element meets at least one cross-sectoral criterion and drawing up a list of potential critical infrastructure elements. It is then possible to select the relevant influential critical element of road infrastructure from the resultant list.

One essential part of the identification is the $3 \mathrm{rd}$ phase of the process, in which the criteria must be defined sensitively. For the definition of the sectoral criteria, the authors recommend the use of input data based on these 5 criteria: (1) transport performance of element (intensity and density of transport and capacity of element), (2) size of the structure, (3) renewal requirements (financial costs and timeline), (5) material value and economic impact (costs for travel and environmental damage).

\section{Step 2: Identification of dependent subsystems}

After the influential element has been selected, the dependent subsystems are identified. It is a good idea to use the KARS method for this (Pacinda 2010). This is a simple method for identifying interconnections of subsystems in a critical infrastructure system. The method and its application are presented in detail in part 2 of this (our) article. 


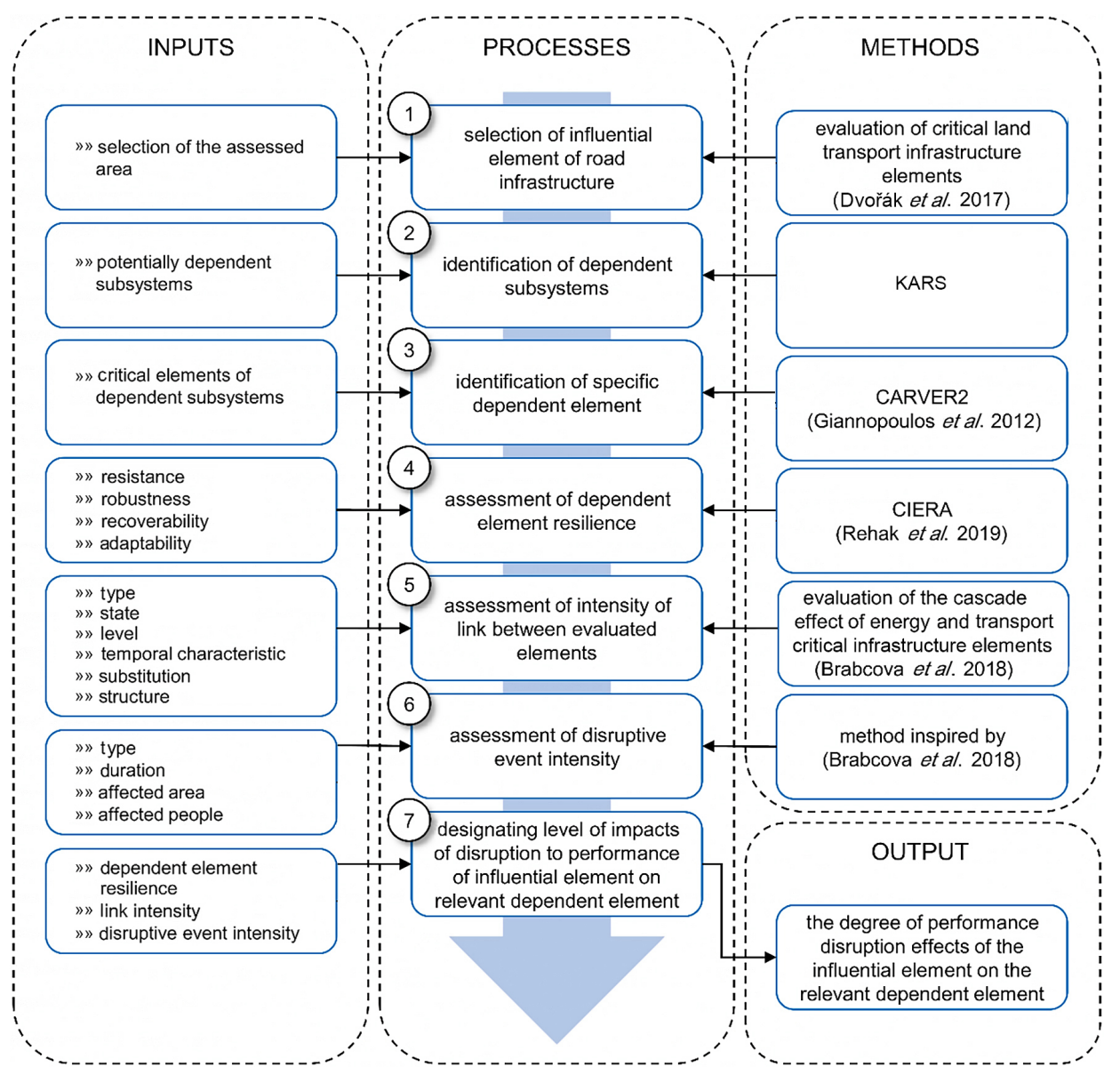

Figure 3. A comprehensive approach to assessing impacts of disruption to performance of road infrastructure elements on dependent subsystems

\section{Step 3: Identification of specific dependent element}

In this step, selecting the specific element to be assessed out of the identified dependent subsystems is necessary. A prerequisite for selecting the relevant element is its significance in terms of the other elements, but this is not a requirement. For this reason, it is a good idea to use the CARVER2 (abbreviation is explained below) method (Giannopoulos et al. 2012), a modified version of an original military method, for the rapid, easy identification of a relevant dependent element. The method serves for the subjective evaluation of the significance of the evaluated elements, and it can also be applied to critical infrastructure elements. When applying this method, there is an evaluation of criticality (C), accessibility (A), recoverability (R), vulnerability $(\mathrm{V})$, espyability $(\mathrm{E})$ and redundancy $(\mathrm{R})$. A point value $(1 \ldots 10)$ is assigned to the specified criteria. The sum of these values gives the resultant significance value, based on which the relevant dependent element is selected for further assessment.

\section{Step 4: Assessment of dependent element resilience}

The next step is an assessment of the selected dependent element's resilience. It is good to use the CIERA method (Rehak et al. 2019) for this. This method was developed with a specific focus on critical infrastructure elements, and it gives a clear overview of the given element's resilience and designates its metric. The designation of the overall resilience metric is based on the average of the values of 3 components: (1) robustness, (2) recoverability, and (3) adaptability. Each of the components is determined by several variables and their measurable items. Point values and weightings are assigned to the individual variable items, and the resultant values of the 3 aforementioned components are derived from them. The total resilience metric is calculated according to equation:

$$
R E=\frac{1}{n} \cdot \sum_{j=1}^{n} K_{j}=\frac{1}{n} \cdot \sum_{j=1}^{n} \sum_{k=1}^{m} V_{k} \cdot w_{k},
$$

where: $R E$ - critical infrastructure element resilience [\%]; $K_{j}-j$ th critical infrastructure element resilience component [\%]; $n$ - total number of resilience determining components; $V_{k}-k$ th critical infrastructure element resilience variable [\%]; $w_{k}-k$ th normalized weight of the $k$ th variable resilience of the critical infrastructure element $[\langle 0 ; 1\rangle]$; $m$ - total number of variables in the $j$ th component.

\section{Step 5: Assessment of intensity of link between evaluated elements}

In the step 5, the intensity of the link between the influential and dependent elements is assessed. It is good to 
proceed based on the article (Brabcova et al. 2018) when evaluating the links between the elements. In this article, the authors give the 6 determinants of link intensity: (1) type, (2) state, (3) level, (4) temporal characteristics, (5) substitution, and (6) structure. Each determinant is assigned a point value $1 \ldots .3$ (Table 3 ), and their weighting coefficients are also designated: type (0.23), state $(0.23)$, level (0.17), temporal characteristic (0.15), substitution (0.12), and structure (0.10). According to equation, the link intensity is calculated, and the resultant link intensity value is expressed in [\%]:

$$
L I=\sum_{i=1}^{n} C_{i} \cdot w_{i} \cdot \frac{100 \%}{C_{i \max }},
$$

where: $L I$ - intensity of the link between the evaluated elements [\%]; $C_{i}$ - point value of the $i$ th criteria; $n$ - number of criteria; $w_{i}$ - normalised weight of the ith criteria [\%]; $C_{i \max }$ - maximum point value of the $i$ th criteria.

\section{Step 6: Assessment of disruptive event intensity}

An intensity assessment must also be performed on a 3rd component influencing the spread of a cascading effect in a critical infrastructure system, which is a disruptive event. The intensity assessment must be performed based on the evaluations given in Section 4.3 of this article. It is evident from the output of this part of the article that the determinants for evaluating the intensity of a disruptive event are its type, duration, impacted territory, and the number of people impacted by the failure. The process for assessing a disruptive event intensity takes its inspiration from assessing link intensity in the preceding step (Brabcova et al. 2018). Each determinant is assigned a point value $1 \ldots 3$ (Table 4 ), and their weighting coefficients are also designated.

An overview of the naturogenic, anthropogenic and technogenic threats and their determinants, including their point values, is given in Table 5 . The given naturogenic and anthropogenic threats are based on the defined threats to road infrastructure (AllTraIn 2015). The technogenic threats are based on the classification of threats, according to Rehak et al. (2019). The weighting coefficients for the individual determinants were calculated using Saaty's pairwise comparison method (Saaty 1977), and their values are as follows: type of disruptive event $(0.12)$, duration of the disruptive event (0.23), affected area (0.42), and affected people (0.23). The disruptive event intensity is calculated according to equation, and the resultant link intensity value is expressed in [\%]:

$$
D E I=\sum_{i=1}^{n} C_{i} \cdot w_{i} \cdot \frac{100 \%}{C_{i \max }},
$$

where: $D E I$ - intensity of the disruptive event [\%]; $C_{i}-$ point value of the $i$ th criteria; $n$ - number of criteria; $w_{i}-$ normalised weight of the $i$ th criteria [\%]; $C_{i \max }-$ maximum point value of the $i$ th criteria.
Step 7: Designating level of impacts of disruption to performance of influential element on relevant dependent element

The step 7 in the evaluation is designating the level of impacts of disruption to the performance of the influential element on the relevant dependent element. This is performed based on a calculation according to equation:

$$
I M L=\frac{(100 \%-R E)+L I+D E I}{3},
$$

where: $I M L$ - level of impacts [\%]; $R E$ - critical infrastructure element resilience [\%]; $L I$ - intensity of the link between the evaluated elements [\%]; DEI - intensity of the

\begin{tabular}{|c|c|c|}
\hline \multicolumn{2}{|c|}{ Criteria determining link intensity $C_{i}$} & $\begin{array}{l}\text { Point } \\
\text { value }\end{array}$ \\
\hline \multirow{4}{*}{ Type of link } & physical link & 3 \\
\hline & geospatial link & 2 \\
\hline & cybernetic link & 2 \\
\hline & logical link & 1 \\
\hline \multirow{3}{*}{ State of link } & mutual dependence & 3 \\
\hline & dependence & 2 \\
\hline & influence & 1 \\
\hline \multirow{3}{*}{ Level of link } & system link & 3 \\
\hline & sector link & 2 \\
\hline & subsector link & 1 \\
\hline \multirow{3}{*}{$\begin{array}{l}\text { Substitution of } \\
\text { link }\end{array}$} & no substitute link exists & 3 \\
\hline & only one substitute link exists & 2 \\
\hline & 2 or more substitute links exist & 1 \\
\hline \multirow{3}{*}{$\begin{array}{l}\text { Temporal } \\
\text { characteristic } \\
\text { link }\end{array}$} & uninterrupted & 3 \\
\hline & periodic & 2 \\
\hline & stand-by & 1 \\
\hline \multirow{3}{*}{$\begin{array}{l}\text { Structure of } \\
\text { link }\end{array}$} & direct & 3 \\
\hline & indirect across one node & 2 \\
\hline & indirect across 2 or more nodes & 1 \\
\hline
\end{tabular}
disruptive event [\%].

Table 3. Determinants and point values of link intensity

Table 4. Criteria of disruptive event intensity determinants and their point values

\begin{tabular}{|l|l|c|}
\hline \multicolumn{2}{|c|}{$\begin{array}{c}\text { Criteria determining the intensity } \\
\text { of disruptive event } C_{i}\end{array}$} & \multirow{2}{*}{ Point value } \\
\hline \multirow{3}{*}{$\begin{array}{l}\text { Type of } \\
\text { disruptive event }\end{array}$} & naturogenic & \multirow{2}{*}{ from Table 5 } \\
\cline { 2 - 3 } & anthropogenic & \\
\cline { 2 - 3 } & technogenic & 3 \\
\hline \multirow{3}{*}{$\begin{array}{l}\text { Duration of a } \\
\text { disruptive event }\end{array}$} & days & 2 \\
\cline { 2 - 3 } & hours & 1 \\
\cline { 2 - 3 } & minutes & 3 \\
\hline \multirow{4}{*}{ Affected area } & over $100 \mathrm{~km}^{2}$ & 2 \\
\cline { 2 - 3 } & $10 \ldots 100 \mathrm{~km}^{2}$ & 1 \\
\cline { 2 - 3 } & up to $10 \mathrm{~km}^{2}$ & 3 \\
\hline \multirow{3}{*}{ Affected people } & over 1000 & 2 \\
\cline { 2 - 3 } & $100 \ldots 1000$ & 1 \\
\cline { 2 - 3 } & up to 100 & \\
\hline
\end{tabular}


Table 5. Point values of naturogenic and anthropogenic disruptive events

\begin{tabular}{|c|c|c|c|}
\hline \multicolumn{3}{|c|}{ Criteria determining type of disruptive event $C_{i}$} & Point \\
\hline & \multirow{13}{*}{$\begin{array}{l}\text { Meteorological } \\
\text { hazards }\end{array}$} & extreme wind & 2 \\
\hline & & extreme rainfall & 2 \\
\hline & & extreme snowfall & 3 \\
\hline & & snow drift & 3 \\
\hline & & sand drift & 1 \\
\hline & & storm surge & 1 \\
\hline & & icing & 2 \\
\hline & & lightning & 1 \\
\hline & & sandstorm & 1 \\
\hline & & fog & 1 \\
\hline & & hail & 1 \\
\hline & & extreme high temperatures & 1 \\
\hline & & extreme low temperatures & 1 \\
\hline \multirow{9}{*}{\multicolumn{2}{|c|}{$\begin{array}{l}\text { Geophysical } \\
\text { hazards }\end{array}$}} & earthquake & 3 \\
\hline & & $\begin{array}{l}\text { ground deformation/ } \\
\text { displacement }\end{array}$ & 3 \\
\hline & & ground subsidence & 2 \\
\hline & & soil liquefaction & 2 \\
\hline & & sinkhole & 2 \\
\hline & & tsunami & 3 \\
\hline & & lava flow & 3 \\
\hline & & lahar & 2 \\
\hline & & ash cloud & 2 \\
\hline \multirow{7}{*}{\multicolumn{2}{|c|}{$\begin{array}{l}\text { Gravitational } \\
\text { hazards }\end{array}$}} & avalanche & 3 \\
\hline & & debris flow & 3 \\
\hline & & shallow landslides & 2 \\
\hline & & deep-seated landslides & 3 \\
\hline & & rock fall & 2 \\
\hline & & rock collapse & 3 \\
\hline & & cliff fall & 3 \\
\hline \multirow{5}{*}{\multicolumn{2}{|c|}{$\begin{array}{l}\text { Hydrological } \\
\text { hazards }\end{array}$}} & $\begin{array}{l}\text { river flood and lake } \\
\text { overflow }\end{array}$ & 3 \\
\hline & & flash flood & 3 \\
\hline & & urban flood & 3 \\
\hline & & groundwater flood & 2 \\
\hline & & outburst flood & 3 \\
\hline \multirow{6}{*}{\multicolumn{2}{|c|}{ Other hazards }} & toppled trees & 2 \\
\hline & & wildfire & 2 \\
\hline & & magnetic storm & 1 \\
\hline & & blackout & 2 \\
\hline & & rodents & 1 \\
\hline & & crossing animals & 1 \\
\hline
\end{tabular}

End of Table 5

\begin{tabular}{|c|c|c|c|}
\hline \multicolumn{3}{|c|}{ Criteria determining type of disruptive event $C_{i}$} & Point \\
\hline \multirow{10}{*}{ 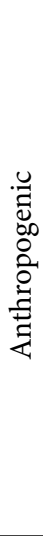 } & \multirow{4}{*}{$\begin{array}{l}\text { Only } \\
\text { intentional }\end{array}$} & ramming & 2 \\
\hline & & sabotage & 2 \\
\hline & & theft & 2 \\
\hline & & cyber attack & 2 \\
\hline & \multirow{2}{*}{$\begin{array}{l}\text { Only } \\
\text { unintentional }\end{array}$} & $\begin{array}{l}\text { excessive vehicle } \\
\text { dimensions }\end{array}$ & 2 \\
\hline & & excessive vehicle weight & 2 \\
\hline & \multirow{4}{*}{$\begin{array}{l}\text { Intentional/ } \\
\text { unintentional }\end{array}$} & blockade & 2 \\
\hline & & fire & 2 \\
\hline & & explosion & 2 \\
\hline & & hazardous release & 2 \\
\hline \multirow{3}{*}{ 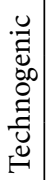 } & \multirow{3}{*}{$\begin{array}{l}\text { Cascading } \\
\text { threats }\end{array}$} & large extent & 3 \\
\hline & & medium extent & 2 \\
\hline & & small extent & 1 \\
\hline
\end{tabular}

The resultant level of impacts is expressed in percentage, where the dependent element resilience, the intensity of link between the elements, and intensity of the disruptive event have the same weight. The specified determinants and their point values can be adjusted for each evaluator's own needs.

In the case of the low resilience of a dependent subsystem towards the cascading of impacts caused by a disruption to the performance of road infrastructure elements, its performance will be disrupted. The scope of this disruption will be derived from the aforementioned components and variables. In the case of dependent subsystems of road infrastructure (i.e., water supply, railway transport, IRS, and healthcare), there may be the following scenarios of performance disruption:

"» damage to water pipes caused by the collapse of the road section;

"» a delay in train transport due to a traffic accident on the level crossing;

"I» the delayed arrival of IRS units at the scene of an accident because a road section was impassable;

"» care for injured and sick patients in a worse state due to delayed transportation to a medical facility.

This list of possible scenarios resulting from disruption is merely illustrative, and in reality, there may be various causes that can also result in cumulative disruption. In addition to the impact on other subsystems, a disruption to the performance of a certain element of road infrastructure often impacts other dependent elements of road infrastructure, especially if they intersect (such as tunnel and intersecting motorway section). 


\section{Conclusions}

The road transport infrastructure is a core subsystem of critical infrastructure. A disruption in the performance of the elements that it includes can impact other subsystems. These elements are major motorway sections, tunnels, bridges, railway level crossings, and intersections. In addition to a disruption to performance, this may spread to other subsystems and negatively impact their performance. In such cases, there is a cascading effect, where the disruption to the performance of the influencing subsystem also reduces the performance of the dependent subsystem. The spread of the cascading effect is conditional on the existence of links between subsystems.

In order to prevent the spread of cascading impacts in the critical infrastructure system, it is essential to know the dependent subsystems of these subsystems where the performance was disrupted. The dependent subsystems of road infrastructure include the water supply, railway transport, IRS, and healthcare, i.e., there are certain links between these subsystems and the road infrastructure. The scope of the cascading effects in the case of a disruption to influencing subsystems will be derived from certain components and their variables. These components are disruptive events (their intensity), links (their intensity), and the dependent subsystem's resilience. Knowing this information may help persons and bodies responsible for protecting the relevant subsystems, e.g., predict the disruption to their performance. They can use this knowledge to draw up measures to strengthen the resilience of the operating elements.

For a comprehensive assessment of a situation, this article presents a newly-created approach to assessing impacts of disruption to the performance of road infrastructure on dependent subsystems. The essence of this approach is a quantitative assessment of the level of impacts arising from a disruption to a critical road infrastructure element and an assessment of its further spread to the critical infrastructure dependent subsystems. The output from the evaluation is a percentage expression of the level of impacts on the relevant subsystem.

The authors' subsequent research will focus on creating a comprehensive tool for predicting disruptions to the performance of the critical road infrastructure element. The framework for creating this tool will define the components and variables influencing the disruption to the performance, identifying selected critical road infrastructure elements, their influential subsystems, and the appropriate methodology.

\section{Funding}

This work was supported by:

"»» the Ministry of the Interior of the Czech Republic Grant No VI20192022151;

"» the Technical University of Ostrava (Czech Republic) - Grant No SP2021/28.

\section{Author contributions}

Conceptualization - David Rehak and David Patrman. Methodology - David Rehak and David Patrman.

Validation - David Rehak, David Patrman, Pavel Fol-

tin, Zdeněk Dvořák and Viktor Skrickij. Investigation - David Rehak, David Patrman and Pavel Foltin.

Writing (original draft preparation) - David Rehak, David Patrman, Pavel Foltin, Zdeněk Dvořák and Viktor Skrickij.

Visualization - David Patrman.

Supervision - David Rehak.

Project administration - David Rehak.

Funding acquisition - David Rehak.

\section{Disclosure statement}

No potential conflict of interest was reported by the authors.

\section{References}

AllTraIn. 2015. All-Hazard Guide for Transport Infrastructure. AllTraIn Project. Bergisch Gladbach, Germany Available from Internet: https://www.alltrain-project.eu

Armenakis, C.; Du, E. X.; Natesan, S.; Persad, R. A.; Zhang, Y. 2017. Flood risk assessment in urban areas based on spatial analytics and social factors, Geosciences 7(4): 123. https://doi.org/10.3390/geosciences7040123

Barrett, C.; Beckman, R.; Channakeshava, K.; Huang, F.; Kumar, V. S. A.; Marathe, A.; Marathe, M. V.; Pei, G. 2010. Cascading failures in multiple infrastructures: from transportation to communication network, in 2010 5th International Conference on Critical Infrastructure (CRIS), 20-22 September 2010, Beijing, China, 1-8.

https://doi.org/10.1109/CRIS.2010.5617569

Basak, S.; Dubey, A.; Bruno, L. 2019. Analyzing the cascading effect of traffic congestion using LSTM networks, in 2019 IEEE International Conference on Big Data (Big Data), 9-12 December 2019, Los Angeles, CA, US, 2144-2153. https://doi.org/10.1109/BigData47090.2019.9005995

Bompard, E.; Napoli, R.; Xue, F. 2009. Analysis of structural vulnerabilities in power transmission grids, International Journal of Critical Infrastructure Protection 2(1-2): 5-12. https://doi.org/10.1016/j.ijcip.2009.02.002

Brabcova, V.; Slivkova, S.; Rehak, D.; Toseroni, F.; Havko, J. 2018. Assessing the cascading effect of energy and transport critical infrastructure elements: case study, Communications - Scientific Letters of the University of Žilina 20(2): 8-15.

https://doi.org/10.26552/com.C.2018.2.8-15

Brunclik, M.; Vogal, L.; Foltin, P. 2018. Computer modelling and simulation of the supply chain in military operation, in 18th International Scientific Conference "Business Logistics in Modern Management”, 11-12 October 2018, Osijek, Croatia, 671-682.

https://hrcak.srce.hr/ojs/index.php/plusm/article/view/7918

Cai, B.; Xie, M.; Liu, Y. H.; Liu, Y.; Feng, Q. 2018. Availabilitybased engineering resilience metric and its corresponding evaluation methodology, Reliability Engineering \& System Safety 172: 216-224. https://doi.org/10.1016/j.ress.2017.12.021 
Calka, B.; Nowak da Costa, J.; Bielecka, E. 2017. Fine scale population density data and its application in risk assessment, Geomatics, Natural Hazards and Risk 8(2): 1440-1455. https://doi.org/10.1080/19475705.2017.1345792

Carhart, N. J.; Rosenberg, G. 2016. A framework for characterising infrastructure interdependencies, International Journal of Complexity in Applied Science and Technology 1(1): 35-60. https://doi.org/10.1504/IJCAST.2016.10002359

Casalicchio, E.; Setola, R.; Bologna, S. 2010. A two-stage approach to simulate interdependent critical infrastructures, in 2010 Complexity in Engineering, 22-24 February 2010, Rome, Italy, 76-78. https://doi.org/10.1109/COMPENG.2010.33

Cats, O.; Hijner, A. M. 2021. Quantifying the cascading effects of passenger delays, Reliability Engineering \& System Safety 212: 107629. https://doi.org/10.1016/j.ress.2021.107629

Cimellaro, G. P. 2016. Urban Resilience for Emergency Response and Recovery: Fundamental Concepts and Applications. Springer. 522 p. https://doi.org/10.1007/978-3-319-30656-8

Chopra, S. S.; Dillon, T.; Bilec, M. M.; Khanna, V. 2016. A network-based framework for assessing infrastructure resilience: a case study of the London metro system, Journal of the Royal Society Interface 13(118): 20160113.

https://doi.org/10.1098/rsif.2016.0113

Cools, M.; Moons, E.; Wets, G. 2010. Assessing the impact of weather on traffic intensity, Weather, Climate, and Society 2(1): 60-68. https://doi.org/10.1175/2009WCAS1014.1

Cumelles, J.; Lordan, O.; Sallan, J. M. 2021. Cascading failures in airport networks, Journal of Air Transport Management 92: 102026. https://doi.org/10.1016/j.jairtraman.2021.102026

De Moel, H.; Jongman, B.; Kreibich, H.; Merz, B.; PenningRowsell, E.; Ward, P. J. 2015. Flood risk assessments at different spatial scales, Mitigation and Adaptation Strategies for Global Change 20(6): 865-890.

https://doi.org/10.1007/s11027-015-9654-z

De Porcellinis, S.; Panzieri, S.; Setola, R. 2009. Modelling critical infrastructure via a mixed holistic reductionistic approach, International Journal of Critical Infrastructures 5(1-2): 86-99. https://doi.org/10.1504/IJCIS.2009.022851

Dekker, M. M.; Panja, D. 2021. Cascading dominates large-scale disruptions in transport over complex networks, PLOS ONE 16(1): e0246077.

https://doi.org/10.1371/journal.pone.0246077

Du, W.-B.; Zhang, M.-Y.; Zhang, Y.; Cao, X.-B.; Zhang, J. 2018. Delay causality network in air transport systems, Transportation Research Part E: Logistics and Transportation Review 118: 466-476. https://doi.org/10.1016/j.tre.2018.08.014

Dudenhoeffer, D. D.; Permann, M. R.; Boring, R. L. 2006a. Decision consequence in complex environments: visualizing decision impact, in 1st Joint Emergency Preparedness and Response/Robotic and Remote Systems Topical Meeting 2006: Sharing Solutions for Emergencies and Hazardous Environments, 11-16 February 2006, Salt Lake City, UT, US, 1: 211-218.

Dudenhoeffer, D. D.; Permann, M. R.; Manic, M. 2006b. CIMS: a framework for infrastructure interdependency modeling and analysis, in Proceedings of the 2006 Winter Simulation Conference, 3-6 December 2006, Monterey, CA, US, 478-485. https://doi.org/10.1109/WSC.2006.323119

Dvořák, Z.; Sventeková, E.; Řehák, D.; Čekerevac, Z. 2017. Assessment of critical infrastructure elements in transport, Procedia Engineering 187: 548-555.

https://doi.org/10.1016/j.proeng.2017.04.413

EC. 2020. Proposal for a Directive of the European Parliament and of the Council on the Resilience of Critical Entities.
COM/2020/829 Final. European Commission (EC), Brussels, Belgium. Available from Internet: https://eur-lex.europa.eu/ legal-content/EN/TXT/?uri=COM:2020:829:FIN

EUCO. 2008. Council Directive 2008/114/EC of 8 December 2008 on the Identification and Designation of European Critical Infrastructures and the Assessment of the Need to Improve their Protection. European Council (EUCO). Available from Internet: http://data.europa.eu/eli/dir/2008/114/oj

Fekete, A. 2020. Critical infrastructure cascading effects. Disaster resilience assessment for floods affecting city of Cologne and Rhein-Erft-Kreis, Journal of Flood Risk Management 13(2): e312600. https://doi.org/10.1111/jfr3.12600

Findley, D. J.; Schroeder, B. J.; Cunningham, C. M.; Brown, T. H. 2015. Highway Engineering: Planning, Design, and Operations. Butterworth-Heinemann. $722 \mathrm{p}$.

Foudi, S.; Osés-Eraso, N.; Tamayo, I. 2015. Integrated spatial flood risk assessment: the case of Zaragoza, Land Use Policy 42: 278-292. https://doi.org/10.1016/j.landusepol.2014.08.002

Giannopoulos, G.; Filippini, R.; Schimmer, M. 2012. Risk Assessment Methodologies for Critical Infrastructure Protection. Part I: a State of the Art. Publications Office of the European Union, Luxembourg. 53 p. https://doi.org/10.2788/22260

He, Z.; Guo, J.-N.; Xu, J.-X. 2019. Cascade failure model in multimodal transport network risk propagation, Mathematical Problems in Engineering 2019: 3615903.

https://doi.org/10.1155/2019/3615903

Hromada, M.; Rehak, D.; Lukas, L. 2021. Resilience assessment in electricity critical infrastructure from the point of view of converged security, Energies 14(6): 1624.

https://doi.org/10.3390/en14061624

IRDR. 2014. IRDR Peril Classification and Hazard Glossary. Integrated Research on Disaster Risk (IRDR). Beijing, China. 28 p.

Jacobsen, J. K. S.; Leiren, M. D.; Saarinen, J. 2016. Natural hazard experiences and adaptations: a study of winter climateinduced road closures in Norway, Norwegian Journal of Geography 70(5): 292-305. https://doi.org/10.1080/00291951.2016.1238847

Jamal, H. 2017. Highway Capacity: Definition, Types \& Factors. Available from Internet: https://www.aboutcivil.org/highwaycapacity-definition-types-factors.html

Johansson, J.; Hassel, H. 2010. An approach for modelling interdependent infrastructures in the context of vulnerability analysis, Reliability Engineering \& System Safety 95(12): 13351344. https://doi.org/10.1016/j.ress.2010.06.010

Keller, S.; Atzl, A. 2014. Mapping natural hazard impacts on road infrastructure - the extreme precipitation in BadenWürttemberg, Germany, June 2013, International Journal of Disaster Risk Science 5(3): 227-241.

https://doi.org/10.1007/s13753-014-0026-1

Kelly, S. 2015. Estimating economic loss from cascading infrastructure failure: a perspective on modelling interdependency, Infrastructure Complexity 2: 7. https://doi.org/10.1186/s40551-015-0010-y

Kozine, I.; Petrenj, B.; Trucco, P. 2018. Resilience capacities assessment for critical infrastructures disruption: the READ framework (part 1), International Journal of Critical Infrastructures 14(3): 199-220.

https://doi.org/10.1504/IJCIS.2018.10015604

Labaka, L.; Hernantes, J.; Sarriegi, J. M. 2016. A holistic framework for building critical infrastructure resilience, Technological Forecasting and Social Change 103: 21-33. https://doi.org/10.1016/j.techfore.2015.11.005

Lam, C. Y.; Tai, K. 2020. Network topological approach to modeling accident causations and characteristics: analysis of railway 
incidents in Japan, Reliability Engineering \& System Safety 193: 106626. https://doi.org/10.1016/j.ress.2019.106626

Ledvinová, M. 2008. Dopravní význam a kapacita pozemních komunikací, Perner's Contacts 3(4): 68-73. Available from Internet: https://pernerscontacts.upce.cz/index.php/perner/ article/view/1317 (in Czech).

Lee, E. E.; Mitchell, J. E.; Wallace, W. A. 2007. Restoration of services in interdependent infrastructure systems: a network flows approach, IEEE Transactions on Systems, Man, and Cybernetics, Part C (Applications and Reviews) 37(6): 13031317. https://doi.org/10.1109/TSMCC.2007.905859

Levinson, D. M.; Kanchi, S. 2002. Road capacity and the allocation of time, Journal of Transportation and Statistics 5(1): 25-46.

Liu, M.; Xu, W. 2013. The approach for critical infrastructure sectors classification using the inoperability input-output model (IIM), in 2013 6th International Conference on Information Management, Innovation Management and Industrial Engineering, 23-24 November 2013, Xian, China, 7-10. https://doi.org/10.1109/ICIII.2013.6703668

MacDermott, Á.; Hurst, W.; Shi, Q.; Merabti, M. 2014. Simulating critical infrastructure cascading failure, in 2014 UKSimAMSS 16th International Conference on Computer Modelling and Simulation, 26-28 March 2014, Cambridge, UK, 324329. https://doi.org/10.1109/UKSim.2014.85

Marzocchi, W.; Garcia-Aristizabal, A.; Gasparini, P.; Mastellone, M. L.; Di Ruocco, A. 2012. Basic principles of multirisk assessment: a case study in Italy, Natural Hazards 62(2): 551-573. https://doi.org/10.1007/s11069-012-0092-X

McDaniels, T.; Chang, S.; Peterson, K.; Mikawoz, J.; Reed, D. 2007. Empirical framework for characterizing infrastructure failure interdependencies, Journal of Infrastructure Systems 13(3): 175-184. https://doi.org/10.1061/(ASCE)1076-0342(2007)13:3(175)

Min, H.-S. J.; Beyeler, W.; Brown, T.; Son, Y. J.; Jones, A. T. 2007. Toward modeling and simulation of critical national infrastructure interdependencies, IIE Transactions 39(1): 57-71. https://doi.org/10.1080/07408170600940005

Nan, C.; Sansavini, G. 2017. A quantitative method for assessing resilience of interdependent infrastructures, Reliability Engineering \& System Safety 157: 35-53.

https://doi.org/10.1016/j.ress.2016.08.013

NIAC. 2009. Critical Infrastructure Resilience: Final Report and Recommendations. National Infrastructure Advisory Council (NIAC), Washington, DC, US. 54 p.

Ouyang, M. 2014. Review on modeling and simulation of interdependent critical infrastructure systems, Reliability Engineering \& System Safety 121: 43-60. https://doi.org/10.1016/j.ress.2013.06.040

Ouyang, M.; Hong, L.; Mao, Z.-J.; Yu, M.-H.; Fei, Q. 2009. A Methodological Approach to Analyse Vulnerability of Interdependent Infrastructures, Simulation Modelling Practice and Theory 17(5): 817-828.

https://doi.org/10.1016/j.simpat.2009.02.001

Pacinda, Š. 2010. Sítová analýza a metoda KARS, The Science for Population Protection 2(1): 1-22. Available from Internet: http://www.population-protection.eu/prilohy/casopis/8/56. pdf (in Czech).

Papilloud, T.; Röthlisberger, V.; Loreti, S.; Keiler, M. 2020. Flood exposure analysis of road infrastructure - comparison of different methods at national level, International Journal of Disaster Risk Reduction 47: 101548.

https://doi.org/10.1016/j.ijdrr.2020.101548
Patrman, D.; Splichalova, A.; Rehak, D.; Onderkova, V. 2019. Factors influencing the performance of critical land transport infrastructure elements, Transportation Research Procedia 40: 1518-1524. https://doi.org/10.1016/j.trpro.2019.07.210

Pederson, P.; Dudenhoeffer, D.; Hartley, S.; Permann, M. 2006. Critical Infrastructure Interdependency Modeling: a Survey of U.S. and International Research. Idaho National Laboratory, Idaho Falls, ID, US. 126 p.

Petit, F. D. P.; Bassett, G. W.; Black, R.; Buehring, W. A.; Collins, M. J.; Dickinson, D. C.; Fisher, R. E.; Haffenden, R. A.; Huttenga, A. A.; Klett, M. S.; Phillips, J. A.; Thomas, M.; Veselka, S. N.; Wallace, K. E.; Whitfield, R. G.; Peerenboom, J. P. 2013. Resilience Measurement Index: an Indicator of Critical Infrastructure Resilience. Argonne National Laboratory (ANL), Argonne, IL, US. 70 p. https://doi.org/10.2172/1087819

Petit, F.; Verner, D.; Brannegan, D.; Buehring, W.; Dickinson, D.; Guziel, K.; Haffenden, R.; Phillips, J.; Peerenboom, J. 2015. Analysis of Critical Infrastructure: Dependencies and Interdependencies. Argonne National Laboratory (ANL), Argonne, IL, US. 50 p. https://doi.org/10.2172/1184636

Poljanšek, K.; Bono, F.; Gutiérrez, E. 2012. Seismic risk assessment of interdependent critical infrastructure systems: the case of European gas and electricity networks, Earthquake Engineering and Structural Dynamics 41(1): 61-79. https://doi.org/10.1002/eqe.1118

Postance, B.; Hillier, J.; Dijkstra, T.; Dixon, N. 2017. Extending natural hazard impacts: an assessment of landslide disruptions on a national road transportation network, Environmental Research Letters 12(1): 014010.

https://doi.org/10.1088/1748-9326/aa5555

Prior, T. 2015. Measuring Critical Infrastructure Resilience: Possible Indicators. Risk And Resilience Report 9. Center for Security Studies (CSS), ETH Zurich, Switzerland. 14 p. Available from Internet: https://css.ethz.ch/en/services/digital-library/ publications/publication.html/190875

Pyrgiotis, N.; Malone, K. M.; Odoni, A. 2013. Modelling delay propagation within an airport network, Transportation Research Part C: Emerging Technologies 27: 60-75.

https://doi.org/10.1016/j.trc.2011.05.017

Quinn, P. 2013. Road density as a proxy for population density in regional-scale risk modeling, Natural Hazards 65(3): 12271248. https://doi.org/10.1007/s11069-012-0379-y

Ramanathan, R. 2004. Indian Transport Towards the New Millennium: Performance, Analysis and Policy. Concept Publishing Co. 212 p.

Rehak, D. 2020. Assessing and strengthening organisational resilience in a critical infrastructure system: case study of the Slovak Republic, Safety Science 123: 104573. https://doi.org/10.1016/j.ssci.2019.104573

Rehak, D.; Markuci, J.; Hromada, M.; Barcova, K. 2016. Quantitative evaluation of the synergistic effects of failures in a critical infrastructure system, International Journal of Critical Infrastructure Protection 14: 3-17. https://doi.org/10.1016/j.ijcip.2016.06.002

Rehak, D.; Senovsky, P.; Hromada, M.; Lovecek, T. 2019. Complex approach to assessing resilience of critical infrastructure elements, International Journal of Critical Infrastructure Protection 25: 125-138. https://doi.org/10.1016/j.ijcip.2019.03.003

Rehak, D.; Hromada, M.; Lovecek, T. 2020. Personnel threats in the electric power critical infrastructure sector and their effect on dependent sectors: overview in the Czech Republic, Safety Science 127: 104698.

https://doi.org/10.1016/j.ssci.2020.104698 
Rehak, D.; Senovsky, P.; Hromada, M.; Lovecek, T.; Novotny, P. 2018. Cascading impact assessment in a critical infrastructure system, International Journal of Critical Infrastructure Protection 22: 125-138. https://doi.org/10.1016/j.ijcip.2018.06.004

Rinaldi, S. M.; Peerenboom, J. P.; Kelly, T. K. 2001. Identifying, understanding, and analyzing critical infrastructure interdependencies, IEEE Control Systems Magazine 21(6): 11-25. https://doi.org/10.1109/37.969131

Rodrigue, J.-P. 2020. The Geography of Transport Systems. 5th edition. Routledge. 480 p. https://doi.org/10.4324/9780429346323

Rogers, C. D. F.; Bouch, C. J.; Williams, S.; Barber, A. R. G.; Baker, C. J.; Bryson, J. R.; Chapman, D. N.; Chapman, L.; Coaffee, J.; Jefferson, I.; Quinn, A. D. 2012. Resistance and resilience - paradigms for critical local infrastructure, Proceedings of the Institution of Civil Engineers - Municipal Engineer 165(2): 73-83. https://doi.org/10.1680/muen.11.00030

Saaty, T. L. 1977. A scaling method for priorities in hierarchical structures, Journal of Mathematical Psychology 15(3): 234281. https://doi.org/10.1016/0022-2496(77)90033-5

Schwab, K. (Ed.). 2019. The Global Competitiveness Report 2019. World Economic Forum (WEF), Geneva, Switzerland. 666 p. Available from Internet: https://www3.weforum.org/docs/ WEF_TheGlobalCompetitivenessReport2019.pdf

Serre, D.; Heinzlef, C. 2018. Assessing and mapping urban resilience to floods with respect to cascading effects through critical infrastructure networks, International Journal of Disaster Risk Reduction 30: 235-243. https://doi.org/10.1016/j.ijdrr.2018.02.018

Setola, R.; De Porcellinis, S.; Sforna, M. 2009. Critical infrastructure dependency assessment using the input-output inoperability model, International Journal of Critical Infrastructure Protection 2(4): 170-178. https://doi.org/10.1016/j.ijcip.2009.09.002

Setola, R.; Theocharidou, M. 2016. Modelling dependencies between critical infrastructures, Studies in Systems, Decision and Control 90: 19-41.

https://doi.org/10.1007/978-3-319-51043-9_2

Simonovic, S. P.; Arunkumar, R. 2016. Comparison of static and dynamic resilience for a multipurpose reservoir operation, Water Resources Research 52(11): 8630-8649. https://doi.org/10.1002/2016WR019551

Stergiopoulos, G.; Kotzanikolaou, P.; Theocharidou, M.; Gritzalis, D. 2015. Risk mitigation strategies for critical infrastructures based on graph centrality analysis, International Journal of Critical Infrastructure Protection 10: 34-44. https://doi.org/10.1016/j.ijcip.2015.05.003

Stergiopoulos, G.; Kotzanikolaou, P.; Theocharidou, M.; Lykou, G.; Gritzalis, D. 2016. Time-based critical infrastructure dependency analysis for large-scale and cross-sectoral failures, International Journal of Critical Infrastructure Protection 12: 46-60. https://doi.org/10.1016/j.ijcip.2015.12.002

Sventekova, E.; Leitner, B.; Dvorak, Z. 2017. Transport critical infrastructure in Slovak Republic, in Proceedings of the 8th International Multi-Conference on Complexity, Informatics and Cybernetics (IMCIC 2017), 21-24 March 2017, Orlando, FL, US, 212-215. Available from Internet: https://www.iiis. org/cds2017/cd2017spring/papers/za357xp.pdf

Theocharidou, M.; Giannopoulos, G. 2015. Risk Assessment Methodologies for Critical Infrastructure Protection. Part II: a New Approach. Publications Office of the European Union, Luxembourg. 40 p. https://doi.org/10.2788/621843

ToL. 2013. Roads Task Force - Technical Note 10: What is the Capacity of the Road Network for Private Motorised Traffic and how has this Changed Over Time? Transport for London
(ToL), UK. 15 p. Available from Internet: https://content.tfl. gov.uk/technical-note-10-what-is-the-capacity-of-the-roadnetwork-for-private-motorised-traffic.pdf

Vlkovský, M.; Ivanuša, T.; Neumann, V.; Foltin, P.; Vlachová, H. 2017. Optimizating cargo security during transport using dataloggers, Journal of Transportation Security 10(3-4): 63-71. https://doi.org/10.1007/s12198-017-0179-4

Voumard, J.; Derron, M.-H.; Jaboyedoff, M. 2018. Natural hazard events affecting transportation networks in Switzerland from 2012 to 2016, Natural Hazards and Earth System Sciences 18(8): 2093-2109.

https://doi.org/10.5194/nhess-18-2093-2018

Zhang, P.; Peeta, S. 2011. A generalized modeling framework to analyze interdependencies among infrastructure systems, Transportation Research Part B: Methodological 45(3): 553-579. https://doi.org/10.1016/j.trb.2010.10.001

Zimmerman, R.; Restrepo, C. E. 2009. Analyzing cascading effects within infrastructure sectors for consequence reduction, in 2009 IEEE Conference on Technologies for Homeland Security, 11-12 May 2009, Waltham, MA, US, 165-170. https://doi.org/10.1109/THS.2009.5168029

Zimmerman, R.; Restrepo, C. E. 2006. The next step: quantifying infrastructure interdependencies to improve security, International Journal of Critical Infrastructures 2(2-3): 215-230. https://doi.org/10.1504/IJCIS.2006.009439 